\title{
Measurement of mean systemic filling pressure after severe hemorrhagic shock in swine anesthetized with propofol-based total intravenous anesthesia: implications for vasopressor-free resuscitation
}

\author{
Athanasios Chalkias ${ }^{1,2}$, Anastasios Koutsovasilis ${ }^{3}$, Eleni Laou ${ }^{1}$, Apostolos Papalois $^{4}$, Theodoros Xanthos ${ }^{5}$ \\ ${ }^{1}$ Department of Anesthesiology, Faculty of Medicine, School of Health Sciences, University of Thessaly, Larissa: ${ }^{2}$ Hellenic Society of Cardiopulmonary \\ Resuscitation, Athens; ${ }^{3}$ rd Department of Internal Medicine, Nikaia General Hospital, Nikaia: ${ }^{4}$ ELPEN, Experimental-Research Centre, Athens, Greece; \\ ${ }^{5}$ European University Cyprus, School of Medicine, Nicosia, Cyprus
}

Background: Mean systemic filling pressure (Pmsf) is a quantitative measurement of a patient's volume status and represents the tone of the venous reservoir. The aim of this study was to estimate Pmsf after severe hemorrhagic shock and cardiac arrest in swine anesthetized with propofol-based total intravenous anesthesia, as well as to evaluate Pmsf's association with vasopressor-free resuscitation.

Methods: Ten healthy Landrace/Large-White piglets aged 10-12 weeks with average weight $20 \pm 1 \mathrm{~kg}$ were used in this study. The protocol was divided into four distinct phases: stabilization, hemorrhagic, cardiac arrest, and resuscitation phases. We measured Pmsf at 5-7.5 seconds after the onset of cardiac arrest and then every 10 seconds until 1 minute postcardiac arrest. During resuscitation, lactated Ringers was infused at a rate that aimed for a mean right atrial pressure of $\leq 4 \mathrm{~mm} \mathrm{Hg}$. No vasopressors were used.

Results: The mean volume of blood removed was $860 \pm 20 \mathrm{ml}$ (blood loss, 61\%) and the bleeding time was $43.2 \pm 2$ minutes while all animals developed pulseless electrical activity. Mean Pmsf was $4.09 \pm 1.22 \mathrm{~mm} \mathrm{Hg}$, and no significant differences in Pmsf were found until 1 minute postcardiac arrest $(4.20 \pm 0.22 \mathrm{~mm} \mathrm{Hg}$ at $5-7.5$ seconds and $3.72 \pm 0.23 \mathrm{~mm} \mathrm{Hg}$ at $55-$ 57.5 seconds; $P=0.102$ ). All animals achieved return of spontaneous circulation (ROSC), with mean time to ROSC being $6.1 \pm 1.7$ minutes and mean administered volume being $394 \pm 20 \mathrm{ml}$. Conclusions: For the first time, Pmsf was estimated after severe hemorrhagic shock. In this study, Pmsf remained stable during the first minute post-arrest. All animals achieved ROSC with goal-directed fluid resuscitation and no vasopressors.

Key Words: anesthesia; hemodynamics; hemorrhagic shock; mean systemic filling pressure; resuscitation

\section{INTRODUCTION}

Circulatory shock is one of the commonest causes of death worldwide, occurring in the majority of patients admitted to the intensive care unit [1]. In patients with shock, venous return is maintained by the pressure gradient between the mean systemic filling pressure (Pmsf)

\section{Original Article}

Received: November 22, 2019 Revised: February 8, 2020 Accepted: February 12, 2020

Corresponding author Athanasios Chalkias Department of Anesthesiology, University Hospital of Larisa, C' Wing, 2nd Floor, PO Box 1425, Mezourlo, Larissa 41110, Greece Tel: $+30-2413502953$ Fax: +30-2413501017 E-mail: thanoschalkias@yahoo.gr

Copyright (๑) 2020 The Korean Society of Critical Care Medicine

This is an Open Access article distributed under the terms of Creative Attributions Non-Commercial License (https:// creativecommons.org/li-censes/by-nc/4.0/) which permits unrestricted noncommercial use, distribution, and reproduction in any medium, provided the original work is properly cited. 
and central venous pressure (CVP) [2]. The Pmsf is a quantitative measurement of the patient's volume status and represents the tone of the venous reservoir [3].

During hemorrhage, physiological compensation may maintain tissue perfusion [4], but the compensatory response to blood loss and time course for development of shock is largely affected by the individual characteristics of the patient. Adjustments within the venous system are critical for maintaining venous pressure during hemorrhage, and mobilization of unstressed blood volume has been characterized as the predominant and most effective mechanism in preserving venous return and thus cardiac output (CO) [5]. Of note, total intravenous anesthesia (TIVA) is frequently used in patients with hemorrhagic shock due to TIVA's well-known advantages, such as predictable and rapid recovery, preservation of hypoxic pulmonary vasoconstriction, and reduction in intracerebral pressure [6]. In TIVA, any combination of intravenous hypnotic(s) and opioid(s) can be used; but in practice, propofol-based TIVA (PTIVA), coupled with other agents depending on the patient's physiological status and the type of procedure, is the most commonly used technique [7].

During the initial stages of acute hemorrhage, venous return, and thus CO is supported by the venous system converting unstressed to stressed blood volumes [5]. However, PTIVA can cause marked reductions in efferent muscle sympathetic nerve activity and plasma catecholamines, reducing systemic vascular resistance (SVR) and aggravating hemodynamics, especially in patients with marginal physiological reserve [68]. Although understanding venous return is crucial for optimizing survival rates, the evidence in these patients remains scarce. In this study, we sought to estimate Pmsf after severe hemorrhagic shock and cardiac arrest in swine anesthetized with PTIVA, as well as to study Pmsf's association with vasopressor-free fluid resuscitation.

\section{MATERIALS AND METHODS}

\section{Ethical Approval}

All animal procedures performed were approved by the Directorate of Veterinary Services according to the national legislation regarding ethical and experimental procedures. These procedures conformed to the guidelines from Directive 2010/ $63 /$ EU of the European Parliament on the protection of animals used for scientific purposes or the current National Institutes of Health guidelines. This manuscript adheres to the applicable Animal Research: Reporting of In Vivo Experiments guidelines.

\section{KEY MESSAGES}

- In this study, mean systemic filling pressure (Pmsf) was estimated after severe hemorrhagic shock and cardiac arrest in swine anesthetized with propofol-based total intravenous anesthesia (PTIVA).

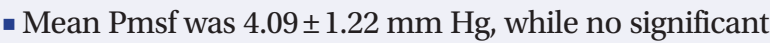
differences in Pmsf were found until 1 minute post-cardiac arrest. All animals achieved return of spontaneous circulation with goal-directed fluid resuscitation and no vasopressors.

- Our findings do not support the early use of vasopressors after hypovolemic cardiac arrest during PTIVA.

\section{Origin and Source of the Animals}

This prospective analysis used 10 healthy Landrace/Large-White piglets aged 10-12 weeks with average weight $20 \pm 1 \mathrm{~kg}$, all purchased from the same breeder (Validakis, Koropi, Greece). These animals were used for teaching purposes in the Experimental Part of the Postgraduate Study Program "Resuscitation" of the University of Athens, Greece (permit no. 1188/282-2014, 4856/15-9-2017).

One week prior to the experiments, the animals were transported to the research facility (Experimental-Research Center Elpen, European Ref Number EL 09 BIO 03) and were acclimatized to laboratory conditions, as previously described [911]. The day before the experimentation, the animals were fasted but had free access to water. All animals received anesthetic and surgical procedures in compliance with the Guide for the Care and Use of Laboratory Animals.

\section{Animal Preparation}

In brief, the animals were premedicated with intramuscular ketamine hydrochloride (10 mg/kg; Merial, Lyon, France), midazolam (0.5 mg/kg; Roche, Athens, Greece), and atropine sulphate (0.05 mg/kg; Demo, Athens, Greece) [12]. The animals were subsequently transported to the operation research facility, and intravascular access was obtained through the auricular veins. Induction of anesthesia was achieved with an intravenous bolus dose of propofol ( $2 \mathrm{mg} / \mathrm{kg}$, Diprivan $1 \% \mathrm{w} / \mathrm{v}$; AstraZeneca, Luton, UK) and fentanyl ( $2 \mu \mathrm{g} / \mathrm{kg}$; Janssen Pharmaceutica, Beerse, Belgium) $[9,10]$. The same researcher performed the intubation with a size 6.0-mm cuffed endotracheal tube while the animals were breathing spontaneously. The endotracheal tube was secured on the lower jaw, and successful intubation was ascertained by auscultation of both lungs while the piglets were ventilated with a self-inflating bag [10]. 
The animals were then immobilized in the supine position on the operating table and were volume-control ventilated (tidal volume $10 \mathrm{ml} / \mathrm{kg}$, I:E 1:2, PEEP $0 \mathrm{~cm} \mathrm{H}_{2} 0$, and $\mathrm{FiO}_{2} 21 \%$; Siare Alpha-Delta Lung Ventilator, Bologna, Italy), while anesthesia was maintained with $0.1 \mathrm{mg} / \mathrm{kg} / \mathrm{min}$ propofol infusion, $0.6 \mu \mathrm{g} / \mathrm{kg} / \mathrm{min}$ fentanyl, and $20 \mu \mathrm{g} / \mathrm{kg} / \mathrm{min}$ cisatracurium. Normocapnia was achieved using continuous monitoring of end-tidal $\mathrm{CO}_{2}$ (Tonocap TC-200-22-01; Engstrom Division, Instrumentarium Corp., Helsinki, Finland), and the respiratory rate was adjusted to maintain an end-tidal $\mathrm{CO}_{2}$ of $35-40 \mathrm{~mm}$ Hg. Pulse oximetry $\left(\mathrm{SpO}_{2}\right)$ was monitored throughout the experiment. Body temperature was monitored by a rectal temperature probe and was maintained between $38.5^{\circ} \mathrm{C}$ and $39.5^{\circ} \mathrm{C}$ with a heating blanket.

Electrocardiographic monitoring was performed using leads I, II, III, aVR, aVL, and aVF, which were connected to a monitor (Mennen Medical, Envoy; Papapostolou, Athens, Greece) [12]. The monitor electronically calculated the heart rate. For measurement of aortic pressures, an arterial catheter (model 6523, USCI CR, Bart; Papapostolou, Athens, Greece) was inserted and forwarded into the descending aorta after surgical preparation of the right internal carotid artery. The systolic (SAP) and diastolic (DAP) arterial pressures were recorded, and mean arterial pressure (MAP) was determined by electronic integration of the aortic blood pressure waveform [11]. The left internal jugular vein was also cannulated, and a Swan-Ganz catheter (Opticath 5.5F, 75 cm; Abbott, Ladakis, Athens, Greece) was inserted into the right atrium. Intravascular catheters were attached to pressure transducers that were aligned to the level of the right atrium and were calibrated before their use. This allowed the recording of CVP and arterial pressures.

CO was measured as the product of time-velocity integral of Doppler transaortic flow, the diameter of the aortic valve, and heart rate; SVR was calculated using the formula SVR=(MAP-
$\mathrm{CVP}) / \mathrm{CO} \times 80$, as previously described $[10,11]$. Coronary perfusion pressure (CPP) was electronically calculated as the difference between minimal DAP and the simultaneously measured right atrial diastolic pressure [12]. Arterial blood gases were measured on a blood-gas analyzer (IRMA SL Blood Analysis System, Part 436301; Diametrics Medical Inc, Roseville, MN, USA; $\mathrm{pH}, \mathrm{pO}_{2}, \mathrm{pCO}_{2}$ ). Baseline data were collected after allowing each animal to stabilize for a 30 -minute period.

\section{Experimental Protocol}

The protocol simulated a major hemorrhage scenario and has been previously described [11]. In brief, the protocol was divided into four distinct phases: stabilization, hemorrhagic, cardiac arrest, and resuscitation phases (Figure 1). All animals were treated by the same researchers.

\section{Stabilization phase}

After induction of anesthesia and instrumentation for recording of hemodynamic variables, swine were allowed to stabilize for 30 minutes. Once a steady state was achieved, baseline measurements including all variables previously mentioned were obtained.

\section{Hemorrhagic phase}

After baseline data collection, acute hemorrhage was induced by repeated removal of $5 \mathrm{ml} / \mathrm{kg}$ from the internal jugular vein in less than 5 minutes; total blood volume was estimated as $7 \%$ of total body weight. In this phase, data were obtained after completion of blood withdrawal.

\section{Cardiac arrest phase}

Cardiac arrest was recognized electrocardiographically and/ or confirmed by loss of arterial pulse. Mechanical ventilation and administration of anesthetics were discontinued simulta-

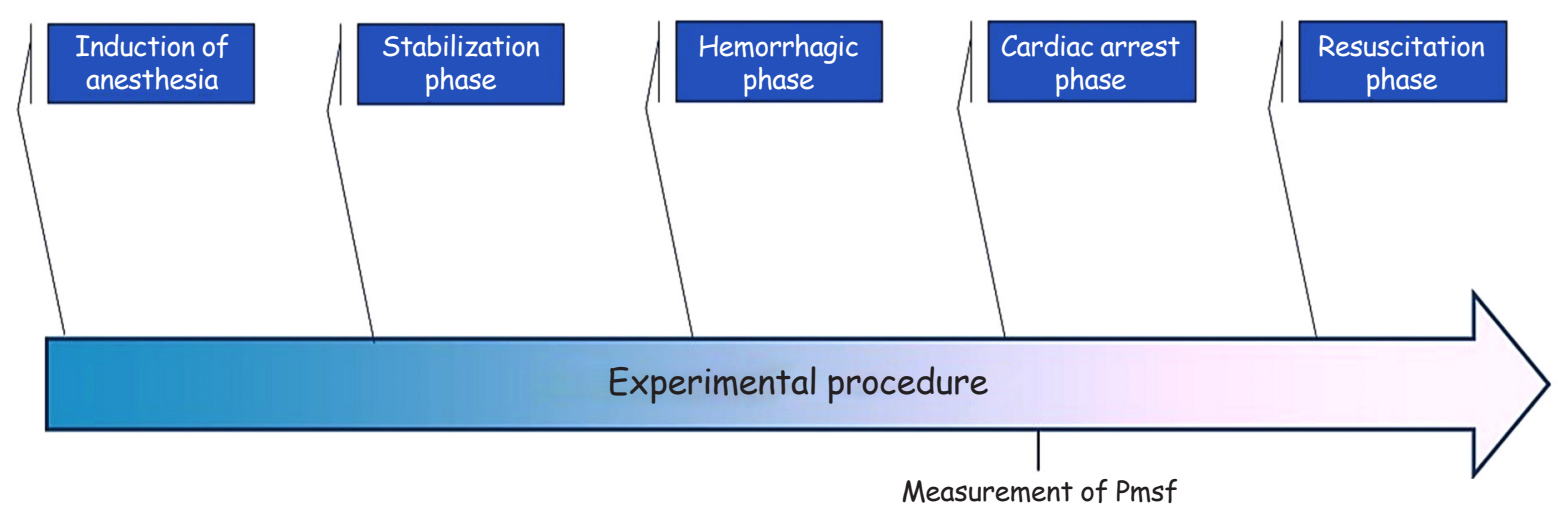

Figure 1. Flowchart of the experimental procedure. Pmsf: mean systemic filling pressure. 
neously with the onset of cardiac arrest.

\section{Resuscitation phase}

After the first minute of cardiac arrest and measurement of Pmsf, resuscitation was immediately initiated with ventilation in $100 \%$ oxygen and chest compressions at a rate of $100 / \mathrm{min}$ (LUCAS; Jolife, Lund, Sweden), while iv infusion of lactated Ringers was started at a rate that aimed for a mean right atrial pressure (RAP) of $\leq 4 \mathrm{~mm} \mathrm{Hg}$. No vasopressors were administered during the study period. Successful resuscitation was defined as restoration of spontaneous circulation (ROSC) with a MAP of at least $60 \mathrm{~mm} \mathrm{Hg}$ for a minimum of 15 minutes. The animals that survived were humanely euthanized by an intravenous overdose of pentobarbital $3 \mathrm{~g}$.

\section{Mean Systemic Filling Pressure}

Shortly after cardiac arrest, significant changes in vasomotor tone occur, while the arterial pressure falls and the venous pressure rises until nearly reaching equilibrium $[13,14]$. This mandates the measurement of Pmsf within the first few seconds after arrest $[13,15]$. However, the hypotension-induced baroreflex withdrawal maintains an antegrade and pulmonary blood flow that may continue for more than 30-60 seconds [14]. As Pmsf may vary among patients, the maximum flow could be better assessed if the time of arrest is more than 20 seconds $[8,16]$. Based on these, we initially measured Pmsf using the equilibrium RAP between 5 and 7.5 seconds after the onset of cardiac arrest, before the reflex response had significantly altered the measured plateau pressure $[14,17,18]$. Then, we continued assessing Pmsf every 10 seconds until 1 minute post-cardiac arrest, provided that the measured plateau pressure had not significantly altered. In our study, Pmsf was measured at six time points (5-7.5, 15-17.5, 25-27.5, 35$37.5,45-47.5$, and $55-57.5$ seconds ).

\section{Animal Inclusion Criteria}

As arteries are much less compliant than veins, transfer of the remaining arterial volume sufficient to equalize pressures throughout the vasculature could not significantly increase Pmsf or affect measurements in our study [17]. In this context, a plateau was considered adequate to allow accurate measurement if RAP rose by less than $1 \mathrm{~mm} \mathrm{Hg}$ over the period from 5 to 7.5 seconds after the onset of cardiac arrest [16]. In our study, all animals had adequate plateau and were included for further analysis.

\section{Statistical Analysis}

Continuous variables were expressed as mean (standard deviation) and categorical variables as percentages. The normal distribution of each variable was assessed by KolmogorovSmirnov's test. Comparisons of continuous variables among the groups were made using analysis of variance or the Kruskal-Wallis test, as appropriate. Univariate analysis was per-

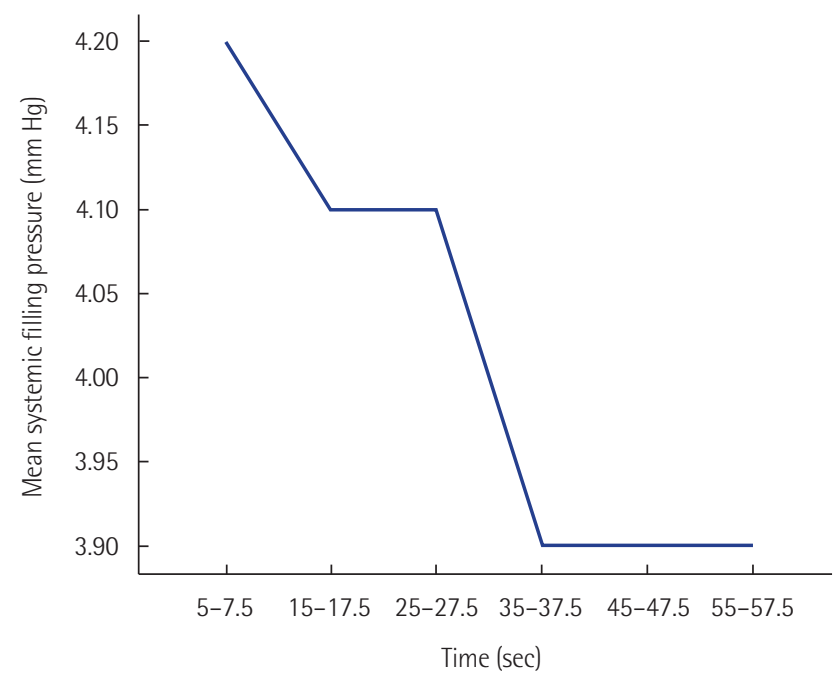

Figure 2. Variation of mean systemic filling pressure after severe hemorrhagic shock and cardiac arrest. No significant differences were observed between the six time points.

Table 1. Peri-arrest parameters of the animals

\begin{tabular}{|c|c|c|c|c|c|c|c|c|c|c|}
\hline \multirow{2}{*}{ Variable } & \multicolumn{10}{|c|}{ Animal } \\
\hline & 1 & 2 & 3 & 4 & 5 & 6 & 7 & 8 & 9 & 10 \\
\hline Blood loss (ml) & 850 & 870 & 860 & 870 & 860 & 870 & 850 & 860 & 850 & 860 \\
\hline Bleeding time (min) & 43 & 44 & 44 & 44 & 42 & 43 & 43 & 43 & 44 & 42 \\
\hline Cardiac arrest rhythm & PEA & PEA & PEA & PEA & PEA & PEA & PEA & PEA & PEA & PEA \\
\hline Time to ROSC (min) & 6 & 6 & 5 & 6 & 5 & 7 & 6 & 7 & 7 & 6 \\
\hline Administered volume (ml) & 400 & 390 & 400 & 390 & 400 & 400 & 390 & 400 & 390 & 380 \\
\hline
\end{tabular}

PEA: pulseless electrical activity; ROSC: return of spontaneous circulation. 
Table 2. Hemodynamic variables during the first minute of cardiac arrest

\begin{tabular}{|c|c|c|c|c|c|c|c|}
\hline \multirow{2}{*}{ Variable } & \multicolumn{7}{|c|}{ Time period (sec) } \\
\hline & $5-7.5$ & $15-17.5$ & $25-27.5$ & $35-37.5$ & $45-47.5$ & $55-57.5$ & P-value \\
\hline HR (beats/min) & $135.80 \pm 8.42$ & $132.32 \pm 6.33$ & $133.60 \pm 5.35$ & $133.51 \pm 5.15$ & $132.64 \pm 4.28$ & $130.62 \pm 2.88$ & 0.102 \\
\hline $\mathrm{SAP}(\mathrm{mm} \mathrm{Hg})$ & $36.91 \pm 1.20$ & $35.02 \pm 1.91$ & $34.33 \pm 0.82$ & $32.25 \pm 0.90$ & $31.07 \pm 0.55$ & $30.29 \pm 0.81$ & 0.048 \\
\hline $\mathrm{DAP}(\mathrm{mm} \mathrm{Hg})$ & $23.52 \pm 0.90$ & $22.67 \pm 1.15$ & $23.55 \pm 2.52$ & $23.13 \pm 1.70$ & $23.11 \pm 1.61$ & $23.04 \pm 1.30$ & 0.223 \\
\hline 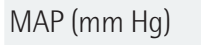 & $27.98 \pm 2.10$ & $26.82 \pm 1.42$ & $27.13 \pm 1.95$ & $26.17 \pm 1.40$ & $25.80 \pm 1.23$ & $25.50 \pm 1.14$ & 0.046 \\
\hline SVR (dyn:s/cm ${ }^{5}$ ) & $575.5 \pm 36.64$ & $534.8 \pm 22.1$ & $489.5 \pm 23.62$ & $469.3 \pm 21.8$ & $429.4 \pm 18.6$ & $401.5 \pm 16.7$ & 0.016 \\
\hline CPP $(\mathrm{mm} \mathrm{Hg})$ & $19.32 \pm 0.73$ & $18.33 \pm 0.55$ & $18.02 \pm 0.57$ & $17.82 \pm 1.13$ & $17.70 \pm 0.92$ & $17.62 \pm 0.66$ & 0.046 \\
\hline $\mathrm{PP}(\mathrm{mm} \mathrm{Hg})$ & $13.38 \pm 0.35$ & $12.35 \pm 0.88$ & $10.78 \pm 1.15$ & $9.12 \pm 1.14$ & $7.96 \pm 1.42$ & $7.25 \pm 0.48$ & 0.040 \\
\hline $\mathrm{SI}$ & $3.72 \pm 0.02$ & $3.77 \pm 0.05$ & $3.92 \pm 0.05$ & $4.14 \pm 0.06$ & $4.27 \pm 0.04$ & $4.31 \pm 0.05$ & 0.048 \\
\hline MSI & $4.95 \pm 0.04$ & $4.92 \pm 0.05$ & $4.90 \pm 0.07$ & $5.12 \pm 0.03$ & $5.15 \pm 0.05$ & $5.13 \pm 0.12$ & 0.088 \\
\hline Pmsf & $4.20 \pm 0.22$ & $4.11 \pm 0.23$ & $4.12 \pm 0.12$ & $3.94 \pm 0.22$ & $3.93 \pm 0.21$ & $3.72 \pm 0.23$ & 0.102 \\
\hline $\mathrm{ETCO}_{2}(\mathrm{~mm} \mathrm{Hg})$ & $12.84 \pm 2.13$ & $11.44 \pm 1.55$ & $10.75 \pm 0.37$ & $10.11 \pm 0.35$ & $9.96 \pm 0.35$ & $9.23 \pm 0.45$ & 0.036 \\
\hline
\end{tabular}

Values are presented as mean \pm standard deviation.

HR: heart rate; SAP: systolic arterial pressure; DAP: diastolic arterial pressure; MAP: mean arterial pressure; SVR: systemic vascular resistance; CPP: coronary perfusion pressure; PP: pulse pressure; SI: shock index; MSI: modified shock index; Pmsf: mean systemic filling pressure; ETCO ${ }_{2}$ : end-tidal carbon dioxide.

formed for the differences of the different situations in different periods of time. The correlations between Pmsf and all other variables in the study were measured with the Pearson correlation coefficient. All tests were two-tailed and a probability value of $\mathrm{P}<0.05$ was considered significant. All statistical analyses were performed using IBM SPSS ver. 21.0 (IBM Corp., Armonk, NY, USA).

\section{RESULTS}

Heart rate and MAP progressively increased and decreased, respectively, while anesthesia remained constant until cardiac arrest occurred. The mean volume of blood removed was $860 \pm$ $20 \mathrm{ml}$ (blood loss $\sim 61 \%$ ) and the bleeding time was $43.2 \pm 2 \mathrm{~min}$ utes, while all animals developed pulseless electrical activity. The peri-arrest parameters in our animals are depicted in $\mathrm{Ta}$ ble 1.

The mean Pmsf value was $4.09 \pm 1.22 \mathrm{~mm} \mathrm{Hg}$ (Figure 2), while no significant differences in Pmsf were observed between the six time points $(4.20 \pm 0.22 \mathrm{~mm} \mathrm{Hg}$ at $5-7.5$ seconds, $3.72 \pm 0.23$ $\mathrm{mm} \mathrm{Hg}$ at $55-57.5$ seconds, $\mathrm{P}=0.102$ ) (Table 2). During the first minute of cardiac arrest, Pmsf was statistically significantly correlated with SAP $(r=0.926, P=0.008)$, MAP $(r=0.926, P=$ 0.007), CVP ( $r=0.926, P=0.008)$, end-tidal carbon dioxide $(\mathrm{r}=0.956, \mathrm{P}=0.004)$, shock index $(\mathrm{r}=-0.916, \mathrm{P}=0.010)$ and modified shock index $(\mathrm{r}=-0.949, \mathrm{P}=0.004)$. There was no statistically significant correlation between Pmsf and DAP $(r=0.370$, $\mathrm{P}=0.446)$. During the first minute after cardiac arrest, statisti- cally significant changes in CPP $(19.32 \pm 0.73 \mathrm{~mm} \mathrm{Hg}$ at $5-7.5$ seconds and $17.62 \pm 0.66 \mathrm{~mm}$ Hg at $55-57.5$ seconds; $\mathrm{P}=0.046$ ) and SVR (575.5 $\pm 36.64 \mathrm{dyn} \cdot \mathrm{s} / \mathrm{cm}^{5}$ at 5-7.5 seconds and $401.5 \pm$ 16.7 dyn $\cdot \mathrm{s} / \mathrm{cm}^{5}$ at $55-57.5$ seconds, $\mathrm{P}=0.016$ ) were observed with time.

All animals achieved ROSC with mean time to ROSC being $6.1 \pm 1.7$ minutes and mean administered volume being $394 \pm$ $20 \mathrm{ml}$.

\section{DISCUSSION}

Hemorrhagic shock is a condition of acute reduction in central blood volume and inadequate tissue perfusion. At the initial stages of hemorrhage $(\sim 10 \%-15 \%)$, the secretion of endogenous catecholamines recruits blood from the unstressed compartment, preserving Pmsf and venous return $[1,19,20]$. At later stages, this mechanism no longer functions and Pmsf decreases proportionally to circulatory volume $[20,21]$. The venous system plays an important role in hemodynamic stability, and Pmsf provides a quantitative measurement of the intravascular filling status independent of cardiac function [22]. However, little evidence exist regarding the measurement of venous tone and Pmsf after hemorrhagic shock and cardiac arrest.

In this study, we were expecting a low Pmsf that would further decrease with time due to the severe hypovolemia and the effects of PTIVA. However, no significant differences in Pmsf were found between the six time points after cardiac arrest, and 
all animals achieved ROSC with fluid resuscitation only. These findings indicate a significant adaptability of the animals to the major hemorrhagic event that merits further analysis.

Pmsf increases with an increase in blood volume or a decrease in venous compliance. In our animals, the hypovolemia-induced sympathetic stimulation resulted in peripheral vasoconstriction and volume recruitment from the unstressed compartment in an attempt to preserve vital organ perfusion during hemorrhage. The severity of shock ( $\sim 61 \%$ blood loss) implies maximal utilization of the unstressed volume prior to cardiac arrest. After the onset of cardiac arrest, the pressure in the small veins and venules, being the "pivoting point" of the swine cardiovascular system, must not have changed substantially [23]. This pressure is less than the capillary pressure, nearly equal to the portal venous pressure, and greater than the RAP [22]. The non-significant differences in Pmsf between the six time points indicate a preserved vascular tone, which, together with the goal-directed fluid administration (RAP $\leq 4$ $\mathrm{mm} \mathrm{Hg}$ ), preserved venous return without the need for an exogenous vasopressor.

Administration of vasopressors in the early stages of hemorrhagic shock remains controversial. Vasopressors are usually used in the presence of life-threatening hypotension and absence of response to fluid therapy or the presence of vasoplegia [24]. Also, administration of anesthetics at any stage of shock may exacerbate hemodynamics; initiation of vasopressor therapy with ongoing volume replacement in order to maintain an adequate tissue perfusion seems rational. However, vasopressor administration in the absence of adequate volume resuscitation may worsen the outcome [25]. Furthermore, a recent post-hoc analysis of a prospective, multicenter, observational study reported that epinephrine administered during in-hospital resuscitation was associated with a lower 7-day survival rate in patients with out-of-hospital cardiac arrest following trauma. The authors suggested that resuscitation without epinephrine in traumatic cardiac arrest should be further studied [26]. Interestingly, our findings indicate that exogenous vasopressors may not always be necessary in severe hemorrhagic shock and/or hypovolemic cardiac arrest and should be carefully titrated during the early stage of resuscitation. Maintaining venous return is crucial; therefore rapid and/or liberal vasopressor and fluid administration may lead to an excessive increase in venous resistance and RAP, respectively, aggravating venous return and CO $[1,3,21]$. In a porcine model of hemorrhage resuscitation, the slope of RAP exceeded peripheral venous pressure when pulmonary artery occlusion pressure increased to more than $10 \mathrm{~mm} \mathrm{Hg}$ during volume resuscitation, causing the pressure gradient for venous return to progressively decrease [27]. As even slight changes in blood volume caused by sympathetic activity can have large effects on Pmsf (which is known to increase almost linearly) [28], different resuscitation practices than currently recommended may be needed in order to improve survival rates in hemorrhagic shock or hypovolemic cardiac arrest [6,29-31].

Our results add to the evidence suggesting that changes in Pmsf can be used to assess systemic compliance and guide the choice between fluids or vasopressors [32]. Although Pmsf is not easy to understand, it could be integrated in the future as another monitoring parameter to understand the patient's condition and to guide personalized physiology-guided resuscitation. According to our findings, an SVR of $>400 \mathrm{dyn} \cdot \mathrm{s} / \mathrm{cm}^{5}$ may also indicate a preserved arterial tone and no need for exogenous vasopressors. Nevertheless, the optimal dose and time of vasopressor administration in relation to Pmsf or SVR should be further investigated. Of note, new pharmacological agents have shown promising results and may allow the optimization of Pmsf, venous return, and tissue perfusion in hemorrhagic shock and cardiac arrest. Centhaquin, a novel agent under clinical development, was recently evaluated in a Phase II trial and proved highly effective in the resuscitation of hypovolemic shock by increasing MAP and decreasing the volume of administered fluids while maintaining tissue perfusion [32-35].

Furthermore, the potential hemodynamic and organ-protective effects of anesthetics cannot be neglected. Fentanyl attenuates myocardial injury caused by high-dose adrenaline without blunting its hemodynamic effects, protects against myocardial ischemia-reperfusion injury, reduces infarct size, and enhances recovery of cardiac contractile function [36]. Propofol has been reported to improve microcirculatory perfusion and protect against ischemia-reperfusion injury and apoptosis [37]. However, hemorrhagic shock may alter the pharmacology of propofol and increase propofol's end-organ sensitivity [38]. Also, propofol is $96 \%-98 \%$ protein bound, and changes in unbound propofol between bled and unbled animals have not been reported $[39,40]$. Two animal studies have reported that lower concentrations are required to achieve a desired drug effect, while partial resuscitation with lactated Ringers solution nearly eliminated the pharmacokinetic changes and attenuated the pharmacodynamic changes of hemorrhagic shock on propofol $[41,42]$. All these may apply in our animals, in which PTIVA remained constant until the onset of cardiac arrest. Nevertheless, further study is required to assess the protective effects of PTIVA after hypovolemic shock and cardiac arrest. 
The authors recognize several limitations in the interpretation of the present findings. First, the study was conducted on apparently healthy pigs without potential comorbidities or associated traumatic injuries. Another limitation is that we measured Pmsf without addressing passive recoil effects, nonsteady state effects, or volume transfers between the peripheral and central compartments. Also, we did not assess longterm survival due to the study design. However, our swine model simulates the real hemodynamic events of hemorrhagic shock from the onset of pathophysiological manifestations to cardiac arrest, and our results may add to the understanding of Pmsf complexity in critically ill patients. We believe that the findings of this study are important for the understanding of the physiologic basis of goal-directed treatment and the titration of resuscitation efforts to the patient's physiologic response [43].

In conclusion, in swine anesthetized with PTIVA, no significant differences in Pmsf were observed between the six time points after severe hemorrhagic shock and cardiac arrest, while all animals achieved ROSC with goal-directed fluid resuscitation and no vasopressors.

\section{CONFLICT OF INTEREST}

No potential conflict of interest relevant to this article was reported.

\section{ACKNOWLEDGMENTS}

We would like to thank A. Zacharioudaki, E. Karampela, K. Tsarea, M. Karamperi, N. Psychalakis, A. Karaiskos, S. Gerakis and E. Gerakis, and staff members of the ELPEN, Experimental-Research Centre for their assistance during the experiments.

\section{ORCID}

Athanasios Chalkias https://orcid.org/0000-0002-7634-4665 Anastasios Koutsovasilis

https://orcid.org/0000-0003-4436-6445

Eleni Laou https://orcid.org/0000-0002-4113-3083

Apostolos Papalois https://orcid.org/0000-0001-8339-7426

Theodoros Xanthos https://orcid.org/0000-0003-3670-9305

\section{AUTHOR CONTRIBUTIONS}

Conceptualization: AC. Data curation: AC, TX, AP. Formal analysis: AK, EL. Methodology, Project administration, \& Vi- sualization: AC, TX. Writing-original draft: AC, TX, EL. Writing-review \& editing: all authors.

\section{REFERENCES}

1. Gidwani H, Gómez H. The crashing patient: hemodynamic collapse. Curr Opin Crit Care 2017;23:533-40.

2. Guyton AC, Hall JE. Cardiac output, venous return, and their regulation. In: Schmitt W, Gruliow R, editors. Textbook of medical physiology. 10th ed. Philadelphia: W.B. Saunders; 2000. p. 210-22.

3. Aya HD, Cecconi M. Can (and should) the venous tone be monitored at the bedside? Curr Opin Crit Care 2015;21:240-4.

4. Schiller AM, Howard JT, Convertino VA. The physiology of blood loss and shock: new insights from a human laboratory model of hemorrhage. Exp Biol Med (Maywood) 2017;242: 874-83.

5. Shen T, Baker K. Venous return and clinical hemodynamics: how the body works during acute hemorrhage. Adv Physiol Educ 2015;39:267-71.

6. de Wit F, van Vliet AL, de Wilde RB, Jansen JR, Vuyk J, Aarts LP, et al. The effect of propofol on haemodynamics: cardiac output, venous return, mean systemic filling pressure, and vascular resistances. Br J Anaesth 2016;116:784-9.

7. Al-Rifai Z, Mulvey D. Principles of total intravenous anaesthesia: basic pharmacokinetics and model descriptions. BJA Educ 2016;16:92-7.

8. Magder S. Volume and its relationship to cardiac output and venous return. Crit Care 2016;20:271.

9. Xanthos T, Lelovas P, Vlachos I, Tsirikos-Karapanos N, Kouskouni E, Perrea D, et al. Cardiopulmonary arrest and resuscitation in Landrace/Large White swine: a research model. Lab Anim 2007;41:353-62.

10. Xanthos T, Bassiakou E, Koudouna E, Rokas G, Goulas S, Dontas I, et al. Combination pharmacotherapy in the treatment of experimental cardiac arrest. Am J Emerg Med 2009;27:651-9.

11. Papapanagiotou P, Xanthos T, Gulati A, Chalkias A, Papalois A, Kontouli Z, et al. Centhaquin improves survival in a swine model of hemorrhagic shock. J Surg Res 2016;200:227-35.

12. Raffay V, Chalkias A, Lelovas P, Karlis G, Koutsovasilis A, Papalois A, et al. Addition of glucagon to adrenaline improves hemodynamics in a porcine model of prolonged ventricular fibrillation. Am J Emerg Med 2014;32:139-43.

13. Guyton AC, Polizo D, Armstrong GG. Mean circulatory filling pressure measured immediately after cessation of heart pumping. Am J Physiol 1954;179:261-7.

14. Chalkias A, Xanthos T. Pathophysiology and pathogenesis of 
post-resuscitation myocardial stunning. Heart Fail Rev 2012; 17:117-28.

15. Ogilvie RI, Zborowska-Sluis D, Tenaschuk B. Measurement of mean circulatory filling pressure and vascular compliance in domestic pigs. Am J Physiol 1990;258(6 Pt 2):H1925-32.

16. Schipke JD, Heusch G, Sanii AP, Gams E, Winter J. Static filling pressure in patients during induced ventricular fibrillation. Am J Physiol Heart Circ Physiol 2003;285:H2510-5.

17. Fessler HE, Brower RG, Wise RA, Permutt S. Effects of positive end-expiratory pressure on the gradient for venous return. Am Rev Respir Dis 1991;143:19-24.

18. Jellinek H, Krenn H, Oczenski W, Veit F, Schwarz S, Fitzgerald $\mathrm{RD}$. Influence of positive airway pressure on the pressure gradient for venous return in humans. J Appl Physiol (1985) 2000; 88:926-32.

19. Aya HD, Carsetti A, Bazurro S, Bastoni D, Malbrain ML, Cecconi M. From cardiac output to blood flow auto-regulation in shock. Anaesthesiol Intensive Ther 2015;47 Spec No:s56-62.

20. Maas JJ. Mean systemic filling pressure: its measurement and meaning. Netherlands J Crit Care 2015;19:6-11.

21. Samar RE, Coleman TG. Measurement of mean circulatory filling pressure and vascular capacitance in the rat. Am J Physiol 1978;234:H94-100.

22. Aya HD, Cecconi M. Determinants of Venous Return. In: Pinsky MR, Teboul JL, Vincent JL, editors. Hemodynamic monitoring: lessons from the ICU. Switzerland: Springer Nature; 2019. p. 27-37.

23. Rothe CF. Mean circulatory filling pressure: its meaning and measurement. J Appl Physiol (1985) 1993;74:499-509.

24. Rossaint R, Bouillon B, Cerny V, Coats TJ, Duranteau J, Fernández-Mondéjar E, et al. The European guideline on management of major bleeding and coagulopathy following trauma: fourth edition. Crit Care 2016;20:100.

25. Gupta B, Garg N, Ramachandran R. Vasopressors: do they have any role in hemorrhagic shock? J Anaesthesiol Clin Pharmacol 2017;33:3-8.

26. Yamamoto R, Suzuki M, Hayashida K, Yoshizawa J, Sakurai A, Kitamura N, et al. Epinephrine during resuscitation of traumatic cardiac arrest and increased mortality: a post hoc analysis of prospective observational study. Scand J Trauma Resusc Emerg Med 2019;27:74.

27. Kinsky M, Ribeiro N, Cannesson M, Deyo D, Kramer G, Salter $\mathrm{M}$, et al. Peripheral venous pressure as an indicator of preload responsiveness during volume resuscitation from hemorrhage. Anesth Analg 2016;123:114-22.

28. Hall JE. Cardiac output, venous return, and their regulation. In: Hall JE, editor. Guyton and Hall textbook of medical physi- ology. 13th ed. Philadelphia: Elsevier; 2016. p. 245-58.

29. Hoka S, Yamaura K, Takenaka T, Takahashi S. Propofol-induced increase in vascular capacitance is due to inhibition of sympathetic vasoconstrictive activity. Anesthesiology 1998;89: 1495-500.

30. Ebert TJ. Sympathetic and hemodynamic effects of moderate and deep sedation with propofol in humans. Anesthesiology 2005;103:20-4.

31. Robinson BJ, Ebert TJ, O’Brien TJ, Colinco MD, Muzi M. Mechanisms whereby propofol mediates peripheral vasodilation in humans: sympathoinhibition or direct vascular relaxation? Anesthesiology 1997;86:64-72.

32. Cecconi M, De Backer D, Antonelli M, Beale R, Bakker J, Hofer $\mathrm{C}$, et al. Consensus on circulatory shock and hemodynamic monitoring. Task force of the European Society of Intensive Care Medicine. Intensive Care Med 2014;40:1795-815.

33. Papalexopoulou K, Chalkias A, Pliatsika P, Papalois A, Papapanagiotou P, Papadopoulos G, et al. Centhaquin effects in a swine model of ventricular fibrillation: centhaquin and cardiac arrest. Heart Lung Circ 2017;26:856-63.

34. Kontouli Z, Staikou C, Iacovidou N, Mamais I, Kouskouni E, Papalois A, et al. Resuscitation with centhaquin and 6\% hydroxyethyl starch 130/0.4 improves survival in a swine model of hemorrhagic shock: a randomized experimental study. Eur J Trauma Emerg Surg 2019;45:1077-85.

35. Gulati A, Jain D, Agrawal N, Rahate P, Das S, Chowdhuri R, et al. Clinical phase II results of pmz-2010 (centhaquin) as a resuscitative agent for hypovolemic shock. Crit Care Med 2019; 47:12.

36. da Luz VF, Otsuki DA, Gonzalez MM, Negri EM, Caldini EG, Damaceno-Rodrigues NR, et al. Myocardial protection induced by fentanyl in pigs exposed to high-dose adrenaline. Clin Exp Pharmacol Physiol 2015;42:1098-107.

37. Vasileiou I, Xanthos T, Koudouna E, Perrea D, Klonaris C, Katsargyris A, et al. Propofol: a review of its non-anaesthetic effects. Eur J Pharmacol 2009;605:1-8.

38. Henderson WR, Griesdale DE, Walley KR, Sheel AW. Clinical review. Guyton: the role of mean circulatory filling pressure and right atrial pressure in controlling cardiac output. Crit Care 2010;14:243.

39. Cockshott ID, Douglas EJ, Plummer GF, Simons PJ. The pharmacokinetics of propofol in laboratory animals. Xenobiotica 1992;22:369-75.

40. De Paepe P, Belpaire FM, Rosseel MT, Van Hoey G, Boon PA, Buylaert WA. Influence of hypovolemia on the pharmacokinetics and the electroencephalographic effect of propofol in the rat. Anesthesiology 2000;93:1482-90. 
41. Johnson KB, Egan TD, Kern SE, White JL, McJames SW, Syroid N, et al. The influence of hemorrhagic shock on propofol: a pharmacokinetic and pharmacodynamic analysis. Anesthesiology 2003;99:409-20.

42. Johnson KB, Egan TD, Kern SE, McJames SW, Cluff ML, Pace NL. Influence of hemorrhagic shock followed by crystalloid resuscitation on propofol: a pharmacokinetic and pharmacodynamic analysis. Anesthesiology 2004;101:647-59.

43. Chalkias A, Arnaoutoglou E, Xanthos T. Personalized physiology-guided resuscitation in highly monitored patients with cardiac arrest: the PERSEUS resuscitation protocol. Heart Fail Rev 2019;24:473-80. 